\title{
SPATIAL HEDONIC PRICING MODELS FOR THE VALUATION OF IRRIGATION WATER
}

\section{Z. MALLIOS* \\ A. PAPAGEORGIOU \\ D. LATINOPOULOS \\ P. LATINOPOULOS}

Received: 05/10/07

Accepted: 14/10/08

\author{
Department of Civil Engineering \\ Aristotle University of Thessaloniki \\ GR 54124 Thessaloniki, Greece
}

\begin{abstract}
The main objective of this work is to apply the hedonic pricing method using the methodology of spatial econometrics in order to assess the economic value of irrigation water, as one of the individual attributes of the value of agricultural land parcels. Most of the agricultural land's value attributes, like neighbor characteristics as well as the availability of irrigation water, exhibit a spatial variability. This means that the application of a conventional hedonic pricing model, which is based on the assumption of spatial stationarity, may be inefficient and probably introduce bias in the estimation of several parameters. In fact, the spatial effect, and in particular the spatial dependence is a determinant of the efficiency and consistency of the hedonic model. Therefore, two spatial hedonic pricing models and a conventional one are formulated and implemented. Spatial dependence is incorporated in the modeling in two ways: a) by including a spatially lagged dependent variable (spatial lag model) and b) by including the spatial dependence of the error term (spatial error model). The two spatial econometric models together with a conventional model of multiple regression are applied in a typical rural area of Greece. A key feature of the proposed approach is that a GIS analysis of land parcels is a basic component of the modeling procedure. Results from this application show that the spatial methods increase the efficiency and consistency and reduce the bias of the parameter estimates. Moreover, the spatial error model provides better results and it is, therefore, preferred in order to estimate the value of irrigation water.
\end{abstract}

KEYWORDS: revealed preferences, spatial regression, agricultural water value, GIS.

\section{INTRODUCTION}

Irrigation is a vital component of agricultural production in almost all developed and developing countries. Therefore, in most cases agriculture becomes the major consumer of water among its other uses. This intense water use, in conjunction with its inherent low efficiency, is considered to be a significant burden in agricultural water management, while at the same time restrains a proper allocation of all water resources. Water allocation is indeed a complex, hence, difficult task, especially when decisions on meeting all types of water demand have to be reached under various socio-economic objectives, like economic efficiency, sustainability and equity. Greece is a typical example of a country in which the current water allocation policy highly favours the agricultural sector, causing thus negative impacts on the national water resources sustainability (Latinopoulos, 2005).

In practical terms, it is widely accepted that the design of efficient water allocation systems depends, upon others, on a reliable estimate of the economic value of water, and, therefore, the economic valuation of water used in agriculture is a key issue in water resources management. Still, the economic valuation of irrigation water is not a straightforward process because this type of water becomes a typical non-marketed resource (Agudelo, 2001; Ward and Michelsen, 2002). Appropriate water valuation techniques are based upon either revealed or stated preferences approaches. In the present work the hedonic pricing method - a well 
established revealed preferences technique - is applied for the economic valuation of irrigation water.

Hedonic pricing treats a marketed good, usually land property or house, as a sum of individual goods (characteristics or attributes) that cannot be sold separately in the market (Nelson, 1978). The hedonic pricing method examines the functional relation between a property's value (here the agricultural land value) and its individual attributes and estimates the contribution of the latter to the former. The value of any land parcel depends on several characteristics as its size, its land use (e.g. cultivated crops), the irrigation water availability, the location in relation to various places of interest or infrastructures e.g. settlements, urban centers, roads, highways, the sea etc. As all these characteristics contribute - either positively or negatively - to the price (value) of each parcel, an implicit price (i.e. a reliable surrogate of the value) for anyone of these characteristics can be estimated.

The above mentioned characteristics, that is, the attributes of the marketed good, have, more or less, a spatial character and this is an important problem in the application of the hedonic pricing method, because of the spatial autocorrelation of the data used in the hedonic pricing function (Tietenberg and Folmer, 2007). In this work, an approach to confront the problem of spatial autocorrelation is presented, using two rather new tools for the hedonic pricing method. More analytically, the data sample that is used in formulating the hedonic pricing function is formed by employing a suitable geographical information systems (GIS) software in order to ensure both the completeness and precision of data related to the independent variables (attributes) of the hedonic pricing model. On the other hand, the hedonic pricing function is evaluated by implementing spatial regression models that are overall assessed by comparing their performance against a conventional multiple regression model based on the ordinary least square (OLS) method.

\section{METHODOLOGY}

According to the theory of hedonic pricing, the price of a commodity (the agricultural land in our case) can be attributed to a vector of $n$ characteristics, denoted by $\mathbf{x}=\left(x_{1}, x_{2}, \ldots, x_{n}\right)$ through a direct (functional) relationship (Lancaster, 1966; Rosen, 1974; Hanley and Spash, 1993). In the present work the prices of agricultural land parcels are assumed to be affected by both spatial and non-spatial characteristics. The non-spatial agricultural land attributes include its size or use, whereas the spatial attributes comprise the so-called neighborhood characteristics, like the local irrigation water availability, the altitude of the land parcel, the distance from the nearest settlement, the nearest road, the nearest highway, the sea etc. Under this type of formulation the function that expresses the relation between the price of any land parcel and all of its characteristics can be written as:

$$
\boldsymbol{p}=\alpha+\beta x+\varepsilon
$$

where $\alpha$ is the constant term, $\boldsymbol{\beta}=\left(\beta_{1}, \beta_{2}, \ldots, \beta_{n}\right)$ is the vector of coefficients that represent the influence of the attributes upon the land parcel's value, and $\varepsilon$ is the error term.

The economic theory does not assign specific rules for the formulation of the functional relation described by equation 1 . Consequently, in the application of the hedonic pricing method many functional forms are frequently used. The most popular of these are the linear, the log - linear, the semi - log linear, the reciprocal and log - inverse form (Triplett, 2004). The choice of the most suitable functional form is facilitated by the criterion of goodness of fit, whereas the estimation of the $\beta_{i}$ coefficients is usually made through the application of an OLS multiple regression technique. On the other hand, the economic interpretation of the coefficients of the independent variables differs, depending on the particular functional form. For example, in the case of the linear model, any coefficient $\beta_{i}$ represents the marginal value of the $i$-th characteristic, while in the log-linear model the same coefficient $\beta_{i}$ represents the elasticity of demand for this specific characteristic (Gujarati, 2003).

In most cases, because of the spatial character of the land parcels attributes, the assumption of an independent and identical distribution of the error term (residuals) is not satisfied due to spatial correlation or heteroskedasticity (Anselin, 1988; Anselin, 2005). As a result, the estimations of OLS multiple regression for the coefficients $\beta_{i}$ of the independent variables of the hedonic pricing function are most probably biased and inconsistent. Therefore, in order to 
check the efficiency in handling the effect of spatial dependence, two of the most frequently used spatial regression models, namely the spatial lag model and the spatial error model, are examined herein against the conventional model of multiple regression.

The spatial lag model is analogous to a time series one. According to this model the land value is considered to be autocorrelated in space. This means that the price of any land parcel does not depend solely on the individual characteristics of land but it also depends partially on the characteristics of the neighbor land parcels. The spatial lag model is formally written for any land parcel as:

$$
p=\rho \boldsymbol{W p}+\alpha+\boldsymbol{\beta} \boldsymbol{x}+\boldsymbol{\varepsilon}
$$

where $\boldsymbol{p}$ is a $m \times 1$ column vector ( $m$ is the number of parcels) and $\boldsymbol{x}$ is the $m \times n$ matrix of explanatory variables. $W$ is the standardized spatial weight $m \times m$ matrix with zero diagonal terms that assigns the potential spatial correlation and the product $\boldsymbol{W p}$ is the spatially lagged dependent variable. Moreover, $\rho$ is the spatial autocorrelation parameter, $\boldsymbol{\alpha}$ is the constant term, $\boldsymbol{\beta}$ is the vector of the coefficients of the independent variables and $\boldsymbol{\varepsilon}$ denotes the vector of the independent and identically distributed error term.

On the other hand, the spatial error model aims at handling the spatial dependence through the error term. The spatial error model takes on the following form:

$$
\begin{gathered}
\boldsymbol{p}=\alpha+\boldsymbol{\beta} \boldsymbol{x}+\boldsymbol{u} \\
\boldsymbol{u}=\lambda \boldsymbol{W} \boldsymbol{u}+\boldsymbol{\varepsilon}
\end{gathered}
$$

In the above model (equation 3 ) all variables and parameters are the same with the previous models, while $\lambda$ is the coefficient of the spatially correlated errors and $\boldsymbol{W u}$ is the spatially lagged error term.

\section{STUDY AREA}

The case study selected for the application of the proposed approach belongs to the greater area of the Municipality of Moudania in Chalkidiki, Greece. This area is mainly a rural region with intense tourist development during the summer period. The resident population is 17,000 while summer visitors (tourists) amount to an annual average of 70,000. The demand for irrigation water sums up to $90 \%$ of the total local consumption of water. The total cultivated area is about 10,500 hectares, of which $35 \%$ are irrigated. The major cultivation of nonirrigated land is wheat, while in the irrigated areas the major cultivation is olive trees (about $70 \%$ of the irrigated land) followed by other kinds of trees (about $15 \%$ ) and vegetables (about $7 \%$ ). The municipality, which consists of nine communities, is limited to the south by a coastline along which several tourist resorts have been dynamically developed during the last few decades. Thus, a quite competitive to the already very high agricultural one domestic water use appears also during the summer period. One the other hand, the sole source of water in the whole area is groundwater pumped from the underlying aquifer. Especially during the summer months about 800 private and 100 municipal pumping wells operate at an almost continuous pace (Latinopoulos, 2003).

The study area extends in a region that belongs to the main watershed of the total administrative area of Moudania and comprises seven of the nine municipal communities ( $\mathrm{N}$. Moudania, Dionisiou, Flogita, Zografou, Portaria, Simantra and Ag. Panteleimon). Apart from its urban parts, the region is exclusively an agricultural land in which the prevailing activity is intensive agriculture. This agricultural land consists of about 11,000 parcels, of which a sample of 1,517 parcels is selected for the application of the hedonic pricing method. The spatial distribution of the selected land parcels is shown in Figure 1.

For the 1,517 land parcels in the study area, which have been selected in order to form the sample of data for the case study, relevant data records were created by implementing the well-known ArcGIS software. Specifically to this end, an add-in toolbar, created with ArcObjects and VisualBasic.NET technology, which enables an accurate and fast retrieval of the data of the land parcels spatial characteristics (Mallios et.al., 2007), was implemented. As mentioned previously, the market value of each land parcel depends on its characteristics and its neighborhood characteristics. Therefore, this add-in toolbar was utilized to calculate the 
individual characteristics of each plot, like its area and the elevation and slope of its centroid. On the other hand, the neighborhood characteristics calculated through the ArcMap add-in toolbar were the distances of each land parcel from the sea, the closest settlement, the municipality center ( $N$. Moudania), as well as from the closest local and the national road. The information for the agricultural land use (crop cultivation) was obtained from the official archives of the Prefecture of Chalkidiki, while the values of the land parcels were assessed by the aid of local experts from the real estate sector. This land value assessment is the only feasible one, as there are no reliable data for the agricultural land transactions, not only in the specific region but in the whole country, due to the particularity of the Greek tax system. All these variables (attributes) are next examined to assess their functional relationship with the land parcels price.

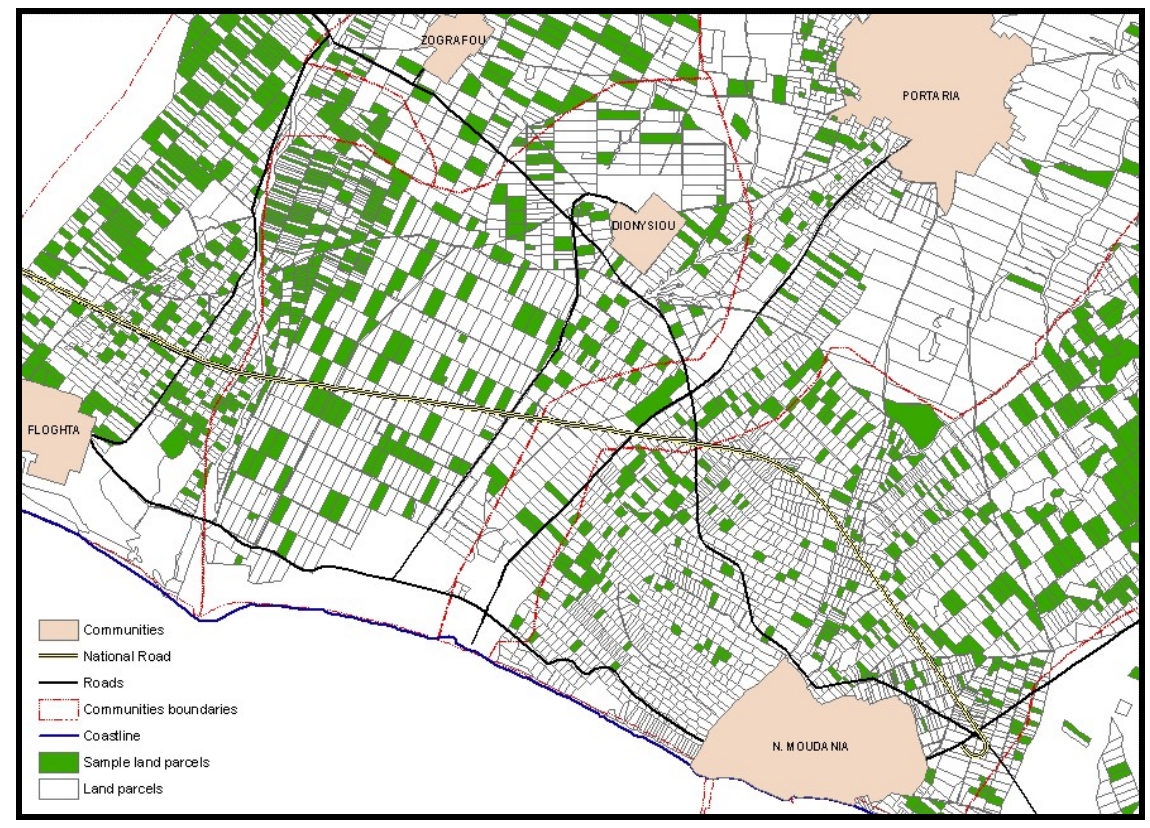

Figure 1. A GIS representation of the case study area

\section{APPLICATION OF THE SPATIAL HEDONIC MODEL}

According to Tripplet (2004), there are two critical issues that should be faced in practically every application of the hedonic pricing method. The first issue relates to the choice of the variables that represent the characteristics of the land parcels and the precision of this data, while the second one concerns the selection of the most suitable functional form to the particular problem at hand. Regarding the precision of data, this is ensured by the tools that are used in this work for their retrieval, whereas their reliability is achieved by the sources from which they have been obtained. As far as the type of the functional form is concerned, several relevant tests led to the selection of the log-linear model as the most appropriate one for the present study. More analytically, the models of equations 1 to 3 were assessed using as dependent variable $p$ the natural logarithm of the LandPrice variable shown in Table 1 and as independent variables the rest of the variables shown also in the same table. In addition, Table 1 presents the definitions and the statistical summary of all the variables that are used for the estimation of the subsequent models.

In Table 2 the diagnostic tests, Moran's I and Lagrange Multiplier (LM), are presented as they are used to test the existence of spatial dependence. These tests are based on the analysis of the residuals of the OLS regression of Table 3. The Moran's I test suggests that there is spatial autocorrelation in the sample data. Because the LM-lag and LM-error statistics are both significant, the robust versions of the statistics were taken into consideration. The robust test of the LM for the spatial lag model is not significant in contrast with the LM for the spatial error model that is significant. Thus, the results shown in Table 2 indicate that, among the three models applied in this study, the spatial error model is the most appropriate one to 
describe the relation between the value of the land parcels and their characteristics (Anselin, 2005).

Table 1. Definition and statistical summary of variables used for hedonic estimations

\begin{tabular}{lllll}
\hline \multicolumn{1}{c}{ Variable } & \multicolumn{1}{c}{ Definition } & Mean & Std. Dev. \\
\hline Ln(LandPrice) & $\begin{array}{l}\text { (Natural Logarithm of) parcel value in } € / \text { ha } \\
\text { (dependent) }\end{array}$ & 9.435 & 1.159 \\
\hline Irrigation & Irrigated field: 1 if yes, 0 if no & 0.301 & 0.459 \\
\hline Ln(Elevation) & (Natural Logarithm of) parcel elevation in $\mathrm{m}$ & 3.748 & 0.751 \\
\hline $\mathrm{Ln}($ AreaHe) & (Natural Logarithm of) parcel area in ha & -0.558 & 0.761 \\
\hline $\mathrm{Ln}$ (DistSea) & (Natural Logarithm of) parcel distance to sea in km & 1.104 & 0.779 \\
\hline Ln(DistSettle) & $\begin{array}{l}\text { (Natural Logarithm of) parcel distance to nearest } \\
\text { settlement in km }\end{array}$ & -0.107 & 0.873 \\
\hline Ln(DistMoud) & $\begin{array}{l}\text { (Natural Logarithm of) parcel distance to city of N. } \\
\text { Moudania in km }\end{array}$ & 1.517 & 0.597 \\
\hline Ln(DistRoad) & $\begin{array}{l}\text { (Natural Logarithm of) parcel distance to nearest } \\
\text { main road in km }\end{array}$ & -0.986 & 1.141 \\
\hline Ln(DistNatRoad) & $\begin{array}{l}\text { (Natural Logarithm of) parcel distance to the national } \\
\text { road in km }\end{array}$ & 0.319 & 1.324 \\
\hline OliveTrees & Olive trees in the plot: 1 if yes, 0 if no & 0.222 & 0.416 \\
\hline
\end{tabular}

Table 2. Diagnostics for spatial dependence

\begin{tabular}{lrcc}
\hline \multicolumn{1}{c}{ Test } & MI/DF & Value & Probability \\
\hline Moran's I (error) & 0.1753 & 35.4443 & 0.0000 \\
\hline Lagrange Multiplier (lag) & 1 & 160.2228 & 0.0000 \\
\hline Robust LM (lag) & 1 & 1.7259 & 0.1889 \\
\hline Lagrange Multiplier (error) & 1 & 1025.9889 & 0.0000 \\
\hline Robust LM (error) & 1 & 867.4919 & 0.0000 \\
\hline Lagrange Multiplier (SARMA) & 2 & 1027.7147 & 0.0000 \\
\hline
\end{tabular}

Table 3. Multiple Linear Regression (OLS) estimates and model's performance statistics

\begin{tabular}{lcccc}
\hline \multicolumn{1}{c}{ Variable } & Coefficient & Std.Error & t-Statistic & Probability \\
\hline Constant & 10.2179 & 0.1525 & 66.9972 & 0.0000 \\
\hline Irrigation & 0.7203 & 0.0605 & 11.9133 & 0.0000 \\
\hline Ln(Elevation) & 0.1702 & 0.0483 & 3.5235 & 0.0004 \\
\hline Ln(AreaHe) & 1.0588 & 0.0230 & 46.0853 & 0.0000 \\
\hline Ln(DistSea) & -0.8047 & 0.0446 & -18.0611 & 0.0000 \\
\hline Ln(DistSettle) & -0.3732 & 0.0192 & -19.4715 & 0.0000 \\
\hline Ln(DistMoud) & -0.3421 & 0.0400 & -8.5599 & 0.0000 \\
\hline Ln(DistRoad) & -0.2045 & 0.0153 & -13.3516 & 0.0000 \\
\hline Ln(DistNatRoad) & 0.2330 & 0.0197 & 11.8184 & 0.0000 \\
\hline OliveTrees & 0.2006 & 0.0671 & 2.9882 & 0.0029 \\
\hline Adj. $R^{2}$ & 0.7141 & & & \\
\hline F-statistic & 421.737 & & & 0.0000 \\
\hline Log-likelihood & -1421.98 & & \\
\hline Akaike info criterion & 2863.96 & & \\
\hline Schwarz criterion & 2917.2 & & 0.0000 \\
\hline Mult. Con. Number & 34.9808 & & 0.0000 \\
\hline Jarque-Bera test & 119.6012 & & \\
\hline Breusch-Pagan test & 355.1428 & & \\
\hline Koenker-Bassett test & 251.7074 & & \\
\hline
\end{tabular}


As mentioned above, Table 3 presents the estimates of the coefficients and the performance statistics of the OLS model of equation 1 . The multicollinearity condition number is $34.98>30$, a fact showing that there is a multicollinearity problem. On the other hand, the Jarque - Bera test is significant, which means that the assumption that the residuals follow the normal distribution is rejected. Also, the tests to detect heteroskedasticity, i.e. Breusch-Pagan and Koenker-Bassett, are also significant and this fact indicates that there are heteroskedasticity problems (Anselin, 2005). As an immediate consequence of all these, the OLS model is not considered to be the most appropriate one to describe the relation between the price of the land parcels and their characteristics.

Table 4. Spatial Lag Model estimates and model's performance statistics

\begin{tabular}{lcccc}
\hline \multicolumn{1}{c}{ Variable } & Coefficient & Std.Error & z-value & Probability \\
\hline Constant & 6.1681 & 0.3587 & 17.1939 & 0.0000 \\
Irrigation & 0.6633 & 0.0581 & 11.4085 & 0.0000 \\
Ln(Elevation) & 0.1362 & 0.0462 & 2.9455 & 0.0032 \\
Ln(AreaHe) & 0.9620 & 0.0238 & 40.4098 & 0.0000 \\
Ln(DistSea) & -0.6760 & 0.0438 & -15.4373 & 0.0000 \\
Ln(DistSettle) & -0.3176 & 0.0187 & -16.9447 & 0.0000 \\
Ln(DistMoud) & -0.1414 & 0.0419 & -3.3771 & 0.0007 \\
Ln(DistRoad) & -0.1976 & 0.0151 & -13.0948 & 0.0000 \\
Ln(DistNatRoad) & 0.1557 & 0.0203 & 7.6878 & 0.0000 \\
OliveTrees & 0.2498 & 0.0645 & 3.8743 & 0.0001 \\
$\rho$ & 0.3966 & 0.0321 & 12.3678 & 0.0000 \\
\hline Adj. $R^{2}$ & 0.7389 & & & \\
F-statistic & & & \\
Log-likelihood & -1360.86 & & \\
Akaike info criterion & 2743.72 & & & \\
\hline Schawarz criterion & 2802.29 & &
\end{tabular}

Table 5. Spatial Error Model estimates and model's performance statistics

\begin{tabular}{lccrc}
\hline \multicolumn{1}{c}{ Variable } & Coefficient & Std.Error & z-value & Probability \\
\hline Constant & 10.1587 & 0.3019 & 33.6497 & 0.0000 \\
\hline Irrigation & 0.7182 & 0.0565 & 12.7218 & 0.0000 \\
\hline Ln(Elevation) & 0.2213 & 0.0587 & 3.7710 & 0.0002 \\
\hline Ln(AreaHe) & 1.0078 & 0.0236 & 42.6507 & 0.0000 \\
\hline Ln(DistSea) & -0.7829 & 0.0750 & -10.4417 & 0.0000 \\
\hline Ln(DistSettle) & -0.3076 & 0.0291 & -10.5589 & 0.0000 \\
\hline Ln(DistMoud) & -0.4378 & 0.1570 & -2.7883 & 0.0053 \\
\hline Ln(DistRoad) & -0.3157 & 0.0171 & -18.4620 & 0.0000 \\
\hline Ln(DistNatRoad) & 0.2479 & 0.0265 & 9.3672 & 0.0000 \\
\hline OliveTrees & 0.1598 & 0.0627 & 2.5510 & 0.0107 \\
\hline$\lambda$ & 0.8892 & 0.0259 & 34.3869 & 0.0000 \\
\hline Adj. $R^{2}$ & 0.7774 & & \\
\hline$F$-statistic & & & \\
\hline Log-likelihood & -1261.6651 & & \\
\hline Akaike info criterion & 2543.33 & & \\
\hline Schawarz criterion & 2596.5752 & & \\
\hline
\end{tabular}

In Tables 3,4 and 5 the estimates of the coefficients $\beta_{i}$ that have been estimated for each model of equations 1,2 and 3 are presented respectively, as well as the performance statistics for each one of them. For the assessment of the three models the same variables 
and the same number of observations are used in order to perform a realistic comparison of the results of the three models.

In Tables 4 and 5 the assessments of the spatial lag model and the spatial error model of equations 1 and 2, respectively, are presented. By comparing the values of the LogLikelihood, the Akaike info criterion and the Schawarz criterion as well as the performance of the other statistics, which are summarized in Table 6, it can be seen that there is a better fit in the spatial error model, meaning that in the region of the Municipality of Moudania this model describes better the relation between the land parcels prices and their characteristics.

Table 6. Spatial Error Model estimates and model's performance statistics

\begin{tabular}{lccc}
\hline \multicolumn{1}{c}{$\begin{array}{c}\text { Performance } \\
\text { Statistics }\end{array}$} & OLS Model & Spatial Lag Model & $\begin{array}{c}\text { Spatial Error } \\
\text { Model }\end{array}$ \\
\hline Adj. R $^{2}$ & 0.7141 & 0.7389 & 0.7774 \\
\hline F-statistic & 421.74 & & \\
\hline Log-likelihood & -1421.98 & -1360.86 & -1261.67 \\
\hline Akaike info criterion & 2863.96 & 2743.72 & 2543.33 \\
\hline Schawarz criterion & 2917.2 & 2802.29 & 2596.58 \\
\hline
\end{tabular}

An important comment on the performance of the spatial error model that has been examined is that it leads to a typical set of variables appearing in similar studies, and that these variables have the expected signs, as shown in equation 4 (Crouter, 1987; Young, 1996; Latinopoulos et. al., 2004). More analytically, due to the high tourist development of the region, the only alternative use of agricultural land is the construction of summer houses for recreational purposes. This explains the fact that the land parcels that are near the sea or/and the major settlements in the area exhibit higher prices. The same fact explains also the negative sign of the relative variables. On the other hand, the value of the constant term is relatively high, which means that there is a high base price for the agricultural land in region. Finally the appearance of the cultivation of olive trees in the hedonic function certifies that indeed this is a high profitable agricultural activity in the region.

$$
\begin{aligned}
\operatorname{Ln}(\text { LandPrice }) & =10.1587+0.1598 \text { OliveTrees }+\mathbf{0} .7182 \text { Irrigation } \\
& +0.2213 \operatorname{Ln}(\text { Elevation })+1.0078 \operatorname{Ln}(\text { Area })-0.7829 \operatorname{Ln}(\text { DistSea }) \\
& -0.3076 \operatorname{Ln}(\text { DistSettle })-0.4378 \text { Ln(DistMoud }) \\
& -0.3157 \text { Ln(DistRoad })+0.2479 \operatorname{Ln}(\text { DistNatRoad })
\end{aligned}
$$

Regarding the value of irrigation water, the importance of its availability - in the sense of an immediate access to the underlying aquifer - in the configuration of the land parcels value is apparent, as expressed by its coefficient in equation 4 . In addition, the trend in the real-estate market, which is that the irrigated land parcels are being sold at about double the price of the non-irrigated ones with similar all their other characteristics, has been confirmed by the model results, as shown immediately after. The economic theory suggests that the interpretation of $\beta_{i}$ coefficients depends on the functional form of the hedonic model (Wooldridge, 2006). For a dummy variable $\mathrm{k}$, like the one that describes the irrigated and non-irrigated land parcels in the log-linear model that is used in the present study, the estimated coefficient provides the exact percentage difference between the irrigated and non-irrigated land as $\exp \left(\beta_{k}\right)-1$. Thus, according to the present spatial error model, where the dummy coefficient of Irrigation in the spatial error model is 0.7182 , the difference between the price of an irrigated land parcel and that of a non-irrigated one, ceteris paribus, is: $\exp (0.7182)-1=1.0507$ or $105.07 \%$. This percentage increase is quite close to a $100 \%$ one, which is the average reported in the real-estate market of the region.

\section{CONCLUSIONS}

The application of the hedonic pricing method for the estimation of the agricultural water use value proved to be quite successful. The overall conclusion is that the use of spatial econometric models in the formulation of the hedonic pricing function leads to a better fitted 
model, as compared to the conventional one of the OLS regression. Furthermore, it is more than obvious that the implementation of geographical information systems in conjunction with the spatial regression models of the hedonic pricing method improves the method's performance and, consequently, suggests such an integrated use of these tools to other similar studies.

\section{ACKNOWLEDGEMENTS}

The current research is supported by grants of the Operational Programme for Education and Initial Vocational Training (O.P. "Education") and a European Union grant (Pythagoras II).

\section{REFERENCES}

1. Agudelo J.I. (2001), The economic valuation of water: Principles and methods. Value of Water Research Report Series No. 5, IHH Delft.

2. Anselin L. (1988), Spatial econometrics: Methods and models. Kluwer Academic Publishers.

3. Anselin L. (2005), Exploring spatial data with GeoDA: A workbook. Center for Spatially Integrated Spatial Social Science (CSISS).

4. Crouter J.P., 1987, Hedonic estimation applied to a water rights market, Land Economics, 63, 259-271.

5. Gujarati D.N. (2003), Basic econometrics (4 ${ }^{\text {th }}$ edition). McGraw-Hill.

6. Hanley N. and Spash C.L. (1993), Cost benefit analysis and the environment. Edward Elgar.

7. Lancaster K.J. (1966), A new approach to consumer theory. Journal of Political Economy, 74, 132-157.

8. Latinopoulos P. (2003), Design of a water potential management plan for public water supply and irrigation in the Municipality of Moudania. Final Report, Research Project, Department of Civil Engineering, AUTh, Thessaloniki (in Greek).

9. Latinopoulos P. (2005), Valuation and pricing of irrigation water: An analysis in Greek agricultural areas. Global NEST Journal, 7, 323-335.

10. Latinopoulos P., Tziakas V. and Mallios Z. (2004), Valuation for irrigation water by the hedonic price method: a case study in Chalkidiki, Greece. Water, Air and Soil Pollution: Focus, 4, 253262.

11. Mallios Z., Papageorgiou A. and Latinopoulos P. (2007), The development of a calculation tool and spatial data retrieval in a Geographical Information Systems environment for the estimation of spatial econometric models. Proceedings of the $6^{\text {th }}$ National Conference of Greek Committee of water resources management, Chania, Greece, 223-230 (in Greek).

12. Nelson J. (1978), Residential choice, hedonic prices, and the demand for urban air quality. Journal of Urban Economics, 5, 357-369.

13. Rosen S. (1974), Hedonic prices and implicit markets: products differentiation in pure competition. Journal of Political Economy, 82, 34-55.

14. Tietenberg, T. and Folmer H. (2007), The international yearbook of environmental and resource economics 2006/2007: A survey of current issues. Edward Elgar.

15. Triplett J. (2004), Handbook on hedonic indexes and quality adjustments in price indexes: Special application to information technology products. STI Working Paper 2004/9 Statistical Analysis of Science, Technology and Industry, OECD.

16. Ward F.A. and Michelsen A. (2002), The economic value of water in agriculture: Concepts and policy applications. Water Policy, 4, 423-446

17. Wooldridge J. (2005), Introductory econometrics: A modern approach ( $3^{\text {rd }}$ edition). Thomson Learning.

18. Young, R. (1996), Measuring economic benefits for water investments and policies. Technical Paper No. 338, World Bank. 